\title{
Assessment of herbal drugs for promising anti-Candida activity
}

\author{
Sameh S. M. Soliman ${ }^{1,2,7^{*}}$, Mohammad H. Semreen ${ }^{1,2}$, Ali A. El-Keblawy ${ }^{3}$, Arbab Abdullah ${ }^{4}$, Priya Uppuluri, 5 \\ and Ashraf S. Ibrahim ${ }^{5,6}$
}

\begin{abstract}
Background: Microbial infections are diverse and cause serious human diseases. Candida albicans infections are serious healthcare-related infections that are complicated by its morphological switching from yeast to hyphae, resistant biofilm formation and mixed infections with bacteria. Due to the increase in drug resistance to currently used antimicrobial agents and the presence of undesirable side effects, the need for safe and effective novel therapies is important. Compounds derived from plants are known for their medicinal properties including antimicrobial activities. The purpose of the study was to compare and evaluate the anti-Candida activities of several medicinal plants in order for the selection of a herbal drug for human use as effective antimicrobial. The selection was taking into considerations two important parameters; parameters related to the selected drug including activity, stability, solubility and toxicity and parameters related to the pathogen including its different dynamic growth and its accompanied secondary bacterial infections.

Methods: Seven different plants including Avicennia marina (Qurm), Fagonia indica (Shoka'a), Lawsania inermis (Henna), Portulaca oleracea (Baq'lah), Salvadora persica (Souwak), Ziziphus spina-Christi (Sidr) and Asphodelus tenuifolius (Kufer) were ground and extracted with ethanol. The ethanol extracts were evaporated and the residual extract dissolved in water prior to testing against Candida albicans in its different morphologies. The antibacterial and cytotoxic effects of the plants extracts were also tested.

Results: Out of the seven tested plants, L. inermis and P. oleracea showed significant anti-Candida activity with MIC $\sim 10 \mu \mathrm{g} / \mathrm{mL}$. Furthermore, both plant extracts were able to inhibit C. albicans growth at its dynamic growth phases including biofilm formation and age resistance. Accompanied secondary bacterial infections can complicate Candida pathogenesis. L. inermis and P. oleracea extracts showed effective antibacterial activities against S. aureus, P. aeruginosa, E. coli, and the multidrug resistant (MDR) A. baumannii and Klebsiella pneumoniae. Both extracts showed no toxicity when measured at their MIC on human erythrocytes.
\end{abstract}

Conclusion: The results from this study suggested that L. inermis and P. oleracea extracts and/or their chemicals are likely to be promising drugs for human use against C. albicans and MDR bacteria.

Keywords: Candida albicans, Antimicrobial, Medicinal plant, Toxicity, Activity, Biofilm

\footnotetext{
* Correspondence: ssoliman@sharjah.ac.ae

${ }^{1}$ Department of Medicinal Chemistry, College of Pharmacy, University of

Sharjah, SharjahPO Box 27272 United Arab Emirates

${ }^{2}$ Sharjah Institute for Medical Research, University of Sharjah, Sharjah, United

Arab Emirates

Full list of author information is available at the end of the article
} International License (http://creativecommons.org/licenses/by/4.0/, which permits unrestricted use, distribution, and reproduction in any medium, provided you give appropriate credit to the original author(s) and the source, provide a link to the Creative Commons license, and indicate if changes were made. The Creative Commons Public Domain Dedication waiver (http://creativecommons.org/publicdomain/zero/1.0/) applies to the data made available in this article, unless otherwise stated. 


\section{Background}

The incidence of microbial infections has increased worldwide, in particular in the healthcare settings [1]. One of the most effective strategies to deal with infections has been the use of antimicrobials in prophylaxis or as therapy. However the fast and widespread incidents of drug resistant among pathogenic microorganisms [2, 3], necessitates the constant search for and development of new antibiotics with novel mechanisms of action [4,5]. The processes of searching for new effective drugs are more complicated for fungal pathogens given the structural similarities between eukaryotes and mammalian cells which often result in effective but toxic drugs [6, 7].

Candida is one of the most common human fungal pathogens [8] and represents the most important cause of opportunistic mycoses worldwide [9]. Candida is known as a major cause of healthcare-related infections among both immunosuppressed and immunocompetent hosts [10]. It is capable of causing both local and hematogenously disseminated infections [11]. The frequency of healthcare-related candidemia increased dramatically over the last decades and it is now considered as one of the most common bloodstream infections in the intensive care units (ICU) $[11,12]$. Despite the increase in Candida infections due to non-albicans species, $C$. albicans remains the main causative agent of candidemia worldwide [12]. Transplantation, immunosuppression, the use of infected devices including catheters and prolonged hospitalization increase the prevalence of invasive candidiasis [13].

The ability of $C$. albicans to switch from yeast to hyphae is recognized as a virulence factor that enables the organism to invade host tissues [14]. Furthermore, Candida spp. produce biofilms on synthetic materials [15]. Candida biofilms develop when organisms adhere to a surface allowing the growth of extensive amount of hyphae and produce extracellular polymers that provide a structural matrix to facilitate further adhesion. Biofilms provide a safe haven for Candida, facilitate drug resistance, and acts as a sources for chronic infections [16]. Catheterrelated microbial biofilms are associated with $90 \%$ of Candida infections and considered as the major cause of morbidity and mortality among hospitalized patients [17].

Plants have been used in traditional herbal medicine for many years [18]. In some parts of the world, plants and herbs are still the primary source of remedies used in treating diseases [19]. For instance, several plant extracts have been reported to have anti-Candida activities including Allium sativum (Garlic) [20, 21], Berberine-containing herbs [22, 23], Cinnamomum verum (Cinnamon) and Origanum vulgare (Oregano) [24-26]. Other plants [27] including Avicennia marina (Qurm) [28], Fagonia indica (Shoka'a) [28], Lawsania inermis (Henna) [29], Portulaca oleracea (Baq'lah) [30], Salvadora persica (Souwak) [31-33] and Ziziphus spina-
Christi (Sidr) [34] were also investigated for their antimicrobial activities. However, studies on their antiCandida activities are still in their infancy. Moreover, none of these plant extracts have been approved by regulatory agency for human use either because of lack of information regarding their efficacy/toxicity and/or lack of defined chemical structures. Here, in a preliminary investigation, we evaluated the in vitro activity of seven different plants native to United Arab Emirates (U.A.E.) against healthcare-related pathogens with emphasis on $C$. albicans. Our ultimate goal is to identify novel drugs with significant activity against Candida Spp. and MDR bacteria expected to complicate Candida infections. Thus it can be defined in their efficacy and toxicity profiles prior to determining their mechanism of action to facilitate their use and evaluation in clinical trials.

\section{Methods}

Plant samples and extraction procedure

Plants were collected from different locations within the city of Sharjah, U.A.E. on April, 2016 as indicated in Table 1 . The plants were taxonomically identified by Dr. Ali El-Keblawy at the Department of Applied Biology, University of Sharjah and voucher specimens were deposited at the University of Sharjah Herbarium on April 2016. The fresh aerial parts of the plants were cut into small sections and ground to very fine paste/powder. The paste/powder was extracted either with ethyl acetate or $95 \%$ ethanol three times followed by filtration. The organic solvent extracts were combined separately and evaporated using rotary evaporator at $50{ }^{\circ} \mathrm{C}$ till dryness. The residual extract either used directly or left at room $\left(\sim 25{ }^{\circ} \mathrm{C}\right)$ or $\sim 4{ }^{\circ} \mathrm{C}$ temperatures for 4 months. The residual extracts were dissolved in sterile water prior to antimicrobial testing and in PBS washing buffer prior to toxicity testing.

\section{Studying the anti-Candida and anti-bacterial activities of plant extracts}

The antimicrobial activity of each plant extract was studied against C. albicans (SC5314) and bacteria strains, namely:

Table 1 Scientific, traditional names and collecting locations of medicinal plants under study

\begin{tabular}{lll}
\hline Plant Scientific Name & Plant Traditional Name & Location \\
\hline Avicennia marina & Qurm & Wadi Shawka, Sharjah \\
Fagonia indica & Shoka'a & Al Dhaid Bridge sharjah \\
Lawsania inermis & Henna & Wadi Shawka, Sharjah \\
Portulaca oleracea & Baq'lah & Wadi Shawka, Sharjah \\
Salvadora persica & Souwak & Al Dhaid bridge, Sharjah \\
Ziziphus spina-Christi & Sidr & Wadi Shawka, Sharjah \\
Asphodelus tenuifolius & Kufer & Wadi Shawka, Sharjah \\
\hline
\end{tabular}


S. aureus, $P$. aeruginosa, E. coli, and the multidrug resistant (MDR) A. baumannii and Klebsiella pneumoniae. All bacterial strains are clinical isolates from patients who were seen at Harbor-UCLA Medical Center, Torrance, CA, U.S.A. The antimicrobial activities of all plant extracts were tested either by disc diffusion assay, in liquid media and by measuring the minimum inhibitory concentration (MIC).

\section{Determination of the antimicrobial activity of plant extracts on agar plates and culture broth media}

The antimicrobial activity of plant extracts on agar plates, liquid broth media and MIC were measured according to a modified version of Clinical and Laboratory Standards Institute (CLSI) [35]. Briefly, $0.1 \mathrm{~mL}$ containing $10^{5} \mathrm{CFU} / \mathrm{mL}$ was spread on Luria-Bertani (LB) agar plates [36]. The plates were then incubated at $37^{\circ} \mathrm{C}$ with filter discs (8 $\mathrm{mm}$ diameter) saturated with different dilutions of plant extracts $(25,50$ and $100 \mu \mathrm{g} / \mathrm{mL})$ for 1 , 2 and 3 days. The inhibition zones $(\mathrm{mm})$ were measured by determining the diameter of the clear area. Similarly, the activity in liquid media was measured by incubating the aforementioned concentrations of plant extracts into LB broth media inoculated with $10^{5} \mathrm{CFU} / \mathrm{mL}$ in 24-well microplates at $37^{\circ} \mathrm{C}$ for 1,2 and 3 days. For the MICs, different concentrations $(1,2.5,5,10,25,50$, and $100 \mu \mathrm{g} / \mathrm{mL}$ ) of plant extracts were added to LB media inoculated with $10^{5} \mathrm{CFU} / \mathrm{mL}$ in 96-well microplates for $24 \mathrm{~h}$ at $37{ }^{\circ} \mathrm{C}$ and the lowest concentration of plant extracts that prevented microbial growth (showed no turbidity) was measured by microplate reader (DYNEX technologies) at $\mathrm{OD}_{600}$. Each test was performed in triplicate. Ketoconazole, colistin and vancomycin were employed as positive controls against Candida, Gram negative bacteria and Gram positive bacteria, respectively. Cultures without plant extracts or antimicrobials were employed as negative control.

The total activity of each plant was calculated according to the following formula [37]. "Total activity $(\mathrm{mL} / \mathrm{g})=$ Amount extracted from $1 \mathrm{~g}(\mathrm{mg}) / \mathrm{MIC}(\mathrm{mg} / \mathrm{mL})$ ".

The minimum fungicidal concentrations (MFC) [38] of both $L$. inermis and $P$. oleracea alcoholic extracts were measured by taking a loop full from $C$. albicans culture broth treated with 10,25 and $50 \mu \mathrm{g} / \mathrm{mL}$ and sub-cultured on LB nutrient agar plates at $37{ }^{\circ} \mathrm{C}$ for $24 \mathrm{~h}$. Growth of $C$. albicans on solid media indicated that particular concentration of the extract was unable to inhibit the fungal growth.

\section{Inhibition of biofilm formation}

The MICs for cells forming biofilm were determined by a microtiter plate assay as described previously [39]. Briefly, each well on a 96-well microtiter plate was filled with $100 \mu \mathrm{L}$ of RPMI-1640 containing $10^{6}$ Candida cells. After $24 \mathrm{~h}$ of incubation at $37{ }^{\circ} \mathrm{C}$, the biofilms were washed and exposed to $100 \mu \mathrm{L}$ of plant extracts at 0.25 , $2.5,12.5 \mu \mathrm{g} / \mathrm{mL}$, and the plates were incubated for $24 \mathrm{~h}$ at $37{ }^{\circ} \mathrm{C}$. The plant extract was removed and the fungal viability was analyzed using 3-(4,5-dimethylthiazol-2-yl)-2,5diphenyl tetrazolium bromide (MTT) (Sigma) [40] and the final absorbance was measured at $540 \mathrm{~nm}$. The MIC of plant extract caused 50\% inhibition of Candida biofilm formation was determined by measuring the metabolic activity of biofilm compared to control [40].

\section{Susceptibility testing of Candida to the antimicrobial activity of plant extracts}

A C. albicans culture was developed by inoculating LB broth with $10^{6} / \mathrm{mL} \mathrm{C}$. albicans for $24 \mathrm{~h}$ at $37{ }^{\circ} \mathrm{C}$. After $24 \mathrm{~h}$, the $C$. albicans culture $\left(\mathrm{OD}_{600}=0.9\right)$ was then treated separately with the MFC $(25 \mu \mathrm{g} / \mathrm{mL})$ of either $L$. inermis or P. oleracea alcoholic extracts or left as control and incubated for another $24 \mathrm{~h}$ at $37{ }^{\circ} \mathrm{C}$. A $5 \mu \mathrm{L}$ of each extract-treated or untreated Candida culture used to inoculate fresh antibiotic-free LB broth culture and incubated for $24 \mathrm{~h}$ at $37{ }^{\circ} \mathrm{C}$ and the $\mathrm{OD}_{600}$ was then measured. All experiments were repeated three times.

\section{Stability testing of plant extracts}

Each plant extract was divided into three portions; one left at room temperature $\left(\sim 25{ }^{\circ} \mathrm{C}\right)$ for 4 months, another one was refrigerated at $\sim 4{ }^{\circ} \mathrm{C}$ for 4 months and a last one used directly once the extraction was done. This was followed by disc diffusion assay of each treatment and the diameter of zone of inhibition (in $\mathrm{mm}$ ) was read at $24 \mathrm{~h}$.

\section{Cytotoxicity assay}

The cytotoxic assay of the plants extracts was measured as the amount of hemoglobin released by the lysis of human erythrocytes [41, 42]. Briefly, fresh whole blood from healthy individual was collected into heparinized vacutainer from Harbor-UCLA Hospital and $1 \mathrm{~mL}$ whole blood was immediately centrifuged at $500 \mathrm{~g}$ for $10 \mathrm{~min}$ using benchtop centrifuge (Eppendorf 5804R Refrigerated Benchtop). The erythrocytes were washed three times with DPBS supplemented with $1 \mathrm{mg} / \mathrm{mL}$ bovine serum albumin (BSA) and then re-suspended to $3 \times 10^{7}$ cells/ $\mathrm{mL}$ in DPBS. Washed cells $\left(3 \times 10^{6}\right.$ cells per well $)$ were incubated with the total plant extracts dissolved in the washing buffer at different concentrations (ranging from 3.6 to $100 \mu \mathrm{g} / \mathrm{mL}$ ) in round-bottomed 96-well plates in a final volume of $200 \mu \mathrm{L}$. Washing buffer and $0.1-1 \%$ Triton $\mathrm{X}-100$ were used as negative and positive controls, respectively. The plate was incubated at $37{ }^{\circ} \mathrm{C}$ for $30 \mathrm{~min}$, followed by $30 \mathrm{~min}$ incubation on ice, and the intact cells were precipitated by centrifugation at $500 \mathrm{~g}$ for $10 \mathrm{~min}$ at $4{ }^{\circ} \mathrm{C}$ and the supernatants $(125 \mu \mathrm{L})$ were transferred to a flat-bottom 96-well plate to 
measure hemoglobin release by absorbance at $405 \mathrm{~nm}$ using a microplate reader. The absorbance values for each sample were subtracted from the absorbance value obtained for washing buffer-treated cells and the hemolytic activity (\%) was calculated. The experiment was conducted in triplicate and the data was analyzed using two-way analysis of variance (ANOVA).

The $50 \%$ cytotoxic concentration $\left(\mathrm{CC}_{50}\right)$ values were calculated as the concentration of plant extract caused $50 \%$ hemolysis compared to $100 \%$ hemolysis of erythrocytes treated with $1 \%$ triton X-100. And selective activities of the extracts were calculated according to the following formula "Selectivity index $(\mathrm{SI})=\left(\mathrm{CC}_{50}\right.$ in $\mathrm{mg} / \mathrm{mL}) /($ MIC in $\mathrm{mg} / \mathrm{mL})$ " [43].

\section{Statistical analysis}

The data was collected and graphed using Microsoft Excel. Data was then exported to Graph Pad 5.0 for Windows (GraphPad Software, La Jolla, CA, USA) for statistical analysis. The effects of plant extracts on $C$. albicans inoculated onto solid agar media, liquid broth and during biofilm formation was analyzed using oneway analysis of variance (ANOVA) using Dunnett's Multiple Comparison Test. $P$ value $<0.05$ was considered as significant.

\section{Results and discussion}

Choosing a medicinal plant to be used as a supplier of antimicrobial drugs is challenging and several issues have to be addressed prior to advancing into clinical trial testing. For example, the efficacy, toxicity and possible kinetics of the drug should be considered.

\section{Extract selection based on screening for anti-Candida activity}

In this study, the potentiality of seven medicinal plants including Avicennia marina, Fagonia indica, Lawsania inermis, Portulaca oleracea, Salvadora persica, Ziziphus
spina-Christi and Asphodelus tenuifolius were compared for their activities against $C$. albicans. The effect of both ethyl acetate and alcoholic (95\% ethanol) plants extracts of the aforementioned medicinal plants were tested against wild type $C$. albicans (SC5314) on LB-agar media using disc diffusion assay. Paper discs saturated with plant extracts at 25,50 , and $100 \mu \mathrm{g} / \mathrm{mL}$ were applied on LB solid media streaked with C. albicans and incubated at $37{ }^{\circ} \mathrm{C}$ for 72 h. A. tenuifolius, S. persica, L. inermis and $P$. oleracea alcoholic extracts inhibited growth of $C$. albicans after $24 \mathrm{~h}$ of incubation (Table 2); However only L. inermis and $P$. oleracea alcoholic extracts showed significant $(P<0.05)$ growth inhibition activity up to $72 \mathrm{~h}$ (Table 2$)$.

Candida infections are complicated by many factors including nutritional conditions, planktonic versus biofilm modes of growth, and the adaptability of the pathogen [44]. All factors together should be considered to provide an effective inhibition of the microbe; so sequential experiments were conducted in order to decide a promising lead extract out of tested plant extracts.

\section{Extract selection based on differential growth conditions of Candida}

Since Candida shows medium-dependent expression of hyphae specific genes with prominent expression in liquid media compared to solid media [45, 46], all plants extracts under study were evaluated for their ability to inhibit C. albicans in liquid LB media. Similar to disc diffusion assay, plant extracts at 25,50 and $100 \mu \mathrm{g} / \mathrm{mL}$ were added to LB broth media inoculated with $C$. albicans and incubated for $72 \mathrm{~h}$ at $37{ }^{\circ} \mathrm{C}$. A. tenuifolius and S. persica as well as L. inermis and P. oleracea alcoholic extracts significantly $(P<0.05)$ inhibited growth of C. albicans to 24 and $72 \mathrm{~h}$ post-incubation, respectively (Table 3). The other plant extracts including A. marina, $F$. indica and Z. spina-Christi increased the growth of C. albicans at lower concentrations, similar to some plant extracts such as green tea leaf extract [47] and

Table 2 Inhibition zones diameters ( $\mathrm{mm}$ ) of alcoholic plant extracts against C. albicans using disc diffusion assay

\begin{tabular}{|c|c|c|c|c|c|c|c|c|c|}
\hline \multirow{3}{*}{$\begin{array}{l}\text { Days of incubation } \\
\text { Extract Conc. }(\mu \mathrm{g} / \mathrm{mL})\end{array}$} & \multicolumn{9}{|c|}{ Effect on C. albicans streaked on solid LB media (zone of inhibition in mm) } \\
\hline & \multicolumn{3}{|l|}{ Day 1} & \multicolumn{3}{|l|}{ Day 2} & \multicolumn{3}{|l|}{ Day 3} \\
\hline & 25 & 50 & 100 & 25 & 50 & 100 & 25 & 50 & 100 \\
\hline A. marina & na & na & na & na & na & na & na & na & na \\
\hline F. indica & na & na & na & na & na & na & na & na & na \\
\hline L. inermis* & $15 \pm 0.5$ & $18 \pm 0.7$ & $22 \pm 1$ & $15 \pm 0.2$ & $17 \pm 0.5$ & $21 \pm 0.4$ & $13 \pm 0.5$ & $16 \pm 0.5$ & $19 \pm 0.3$ \\
\hline P. oleracea* & $11 \pm 1$ & $14 \pm 0.6$ & $17 \pm 0.5$ & $10 \pm 0.2$ & $12 \pm 0.3$ & $15 \pm 0.2$ & $10 \pm 0.2$ & $11 \pm 0.1$ & $13 \pm 0.2$ \\
\hline S. persica & $10 \pm 0.2$ & $12 \pm 0.25$ & $17 \pm 0.5$ & na & na & na & na & na & na \\
\hline Z. spina-Christi & na & na & na & na & na & na & na & na & na \\
\hline A. tenuifolius & $9 \pm 0.1$ & $11 \pm 0.09$ & $16 \pm 0.5$ & na & na & na & na & na & na \\
\hline
\end{tabular}

na: no activity; diameter of the paper disc: $8 \mathrm{~mm}$; ${ }^{*}$ Significant difference with $P$ value $<0.05$ (measured by one-way analysis of variance (ANOVA)). The standard error represents the mean of three replicas 
Table 3 The effect of alcoholic plant extracts on the growth of C. albicans inoculated into LB broth media

\begin{tabular}{|c|c|c|c|c|c|c|c|c|c|}
\hline \multirow{3}{*}{$\begin{array}{l}\text { Days of incubation } \\
\text { Extract Conc. }(\mu \mathrm{g} / \mathrm{mL})\end{array}$} & \multicolumn{9}{|c|}{ Effect on C. albicans inoculated into LB broth (\% growth in relation to negative control) } \\
\hline & \multicolumn{3}{|l|}{ Day 1} & \multicolumn{3}{|l|}{ Day 2} & \multicolumn{3}{|l|}{ Day 3} \\
\hline & 25 & 50 & 100 & 25 & 50 & 100 & 25 & 50 & 100 \\
\hline A. marina & $200 \pm 5.2$ & $100 \pm 3.1$ & $70 \pm 4.2$ & $100 \pm 2.4$ & $100 \pm 2.3$ & $100 \pm 2.3$ & $100 \pm 3.7$ & $100 \pm 5.2$ & $100 \pm 3.1$ \\
\hline F. indica & $180 \pm 0.4$ & $100 \pm 3.2$ & $60 \pm 3.5$ & $100 \pm 0.1$ & $100 \pm 3.5$ & $100 \pm 4.2$ & $100 \pm 4.4$ & $100 \pm 5.4$ & $100 \pm 3.9$ \\
\hline L. inermis* & $0 \pm 0.2$ & $0 \pm 0.4$ & $0 \pm 1.2$ & $8 \pm 0.4$ & $0 \pm 1.0$ & $0 \pm 0.5$ & $25 \pm 0.2$ & $16 \pm 0.4$ & $0 \pm 0.4$ \\
\hline P. oleracea* & $8 \pm 0.5$ & $0 \pm 0.5$ & $0 \pm 1.5$ & $19 \pm 0.3$ & $0 \pm 0.3$ & $0 \pm 0.3$ & $40 \pm 0.1$ & $33 \pm 0.3$ & $27 \pm 0.2$ \\
\hline S. persica* & $15 \pm 0.2$ & $9 \pm 0.6$ & $0 \pm 0.3$ & $35 \pm 0.4$ & $20 \pm 0.2$ & $20 \pm 0.1$ & $100 \pm 0.4$ & $100 \pm 1.1$ & $100 \pm 0.5$ \\
\hline Z. spina-Christi & $250 \pm 2.1$ & $150 \pm 0.8$ & $100 \pm 0.5$ & $100 \pm 0.3$ & $100 \pm 2.4$ & $100 \pm 0.6$ & $100 \pm 1.3$ & $100 \pm 0.9$ & $100 \pm 0.5$ \\
\hline A. tenuifolius* & $23 \pm 0.5$ & $15 \pm 0.3$ & $0 \pm 0.1$ & $50 \pm 0.5$ & $45 \pm 0.2$ & $30 \pm 1.2$ & $100 \pm 1.2$ & $100 \pm 0.4$ & $100 \pm 0.6$ \\
\hline
\end{tabular}

* Significant difference with $P$ value $<0.05$ (measured by one-way analysis of variance (ANOVA)). The standard error represents the mean of three replicas. The growth measured by absorbance at OD600 by microplate reader

cabbage leaf extract [48] that can selectively inhibit and stimulate different microbial growth. All ethyl acetate extracts showed no activity either on solid or liquid media (data not shown).

\section{Extract selection based on growth complication of Candida by morphology changes and biofilm formation}

An important feature of $C$. albicans growth is its ability to switch between yeast and hyphae forms [49]. The hyphae form is importantly required for disease progression by invading host cells and causing tissue damage [50, 51], and for formation of biofilm [52]. Because both $L$. inermis and $P$. oleracea showed significant inhibitory effect on C. albicans in solid and liquid media, they were tested against biofilm formation. Both alcoholic plant extracts showed significant $(P$ value $<0.05)$ inhibitory effect on C. albicans biofilm formation (Fig. 1a) within the range of MIC (Table 4). The MIC of both L. inermis and $P$. oleracea were measured to be $10 \mu \mathrm{g} / \mathrm{mL}$ (Table 4) compared to $1 \mu \mathrm{g} / \mathrm{mL}$ ketoconazole (Sigma) as control. And the minimum fungicidal concentrations (MFC) of both $L$. inermis and P. oleracea was $\leq 25 \mu \mathrm{g} / \mathrm{mL}$.

\section{Extract selection based on growth complication of Candida by bacterial mixed infections}

Another complication with in vivo Candida infection is its frequent ability to form mixed infections with bacterial species including Pseudomonas aeruginosa usually found in combination in biofilm formation and recovered from patient with lung infection [53], Staphylococcus aureus and Escherichia coli in inflamed palatal mucosa, enterococci and Klebsiella in labial lesion and other infections that can induce life-threatening septicemia [54]. Both L. inermis and P. oleracea alcoholic extracts showed consistent broad spectrum antibacterial activity to all tested microorganisms including E. coli, S. aureus, A. baumanii, $K$. pneumoniae and $P$. aeruginosa compared to other aforementioned plant extracts (Fig. 1b). Other plant extracts including A. marina, F. indica, S. persica, Z. spina, and $A$. tenuifolius showed modest species-specific antibacterial activities (Fig. 1b).

\section{Extract selection based on complication of Candida age and resistance}

The relative susceptibility of $C$. albicans to antibiotics is dependent on the age of culture because the culture environment is rapidly changing and the cell populations becomes more physiologically heterogeneous [55] and hence, more resistant with age [56-58]. So it is beneficial to test the effect of both plant extracts on $C$. albicans culture in its stationary phase of growth [59]. A C. albicans culture was developed by growing LB broth inoculated with $C$. albicans for $24 \mathrm{~h}$ prior to treating separately with $L$. inermis or $P$. oleracea alcoholic extracts. Both extracts caused aggregation and precipitation of the C. albicans culture (Fig. 1c). Inoculation of plant extract treated-cultures into fresh antibiotic-free LB broth followed by incubation for $24 \mathrm{~h}$ at $37{ }^{\circ} \mathrm{C}$ showed $>90 \%$ inhibition in growth compared to control LB broth that received the same volume of untreated $C$. albicans culture (Fig. 1c). The results indicated that $C$. albicans cultures showed high sensitivity to both plant extracts even at increased growth rate and the effect of the two plant extracts are cidal.

\section{Selection based on extract stability}

Usually antimicrobials are under suspicion of diminishing activities either because of admixture and dispensing to be stored at home or shelf storage before use [60]. The stability during shelf half-life storage of both $L$. inermis and P. oleracea alcoholic extracts were tested by storing both plant extracts for 4 months at room temperature $\left(\sim 25{ }^{\circ} \mathrm{C}\right)$ followed by incubation with aforementioned microbes. The results showed that both extracts possess activities similar to those used fresh or stored at $4{ }^{\circ} \mathrm{C}$ (data not shown). The results indicated that both plant extracts are stable at wide 

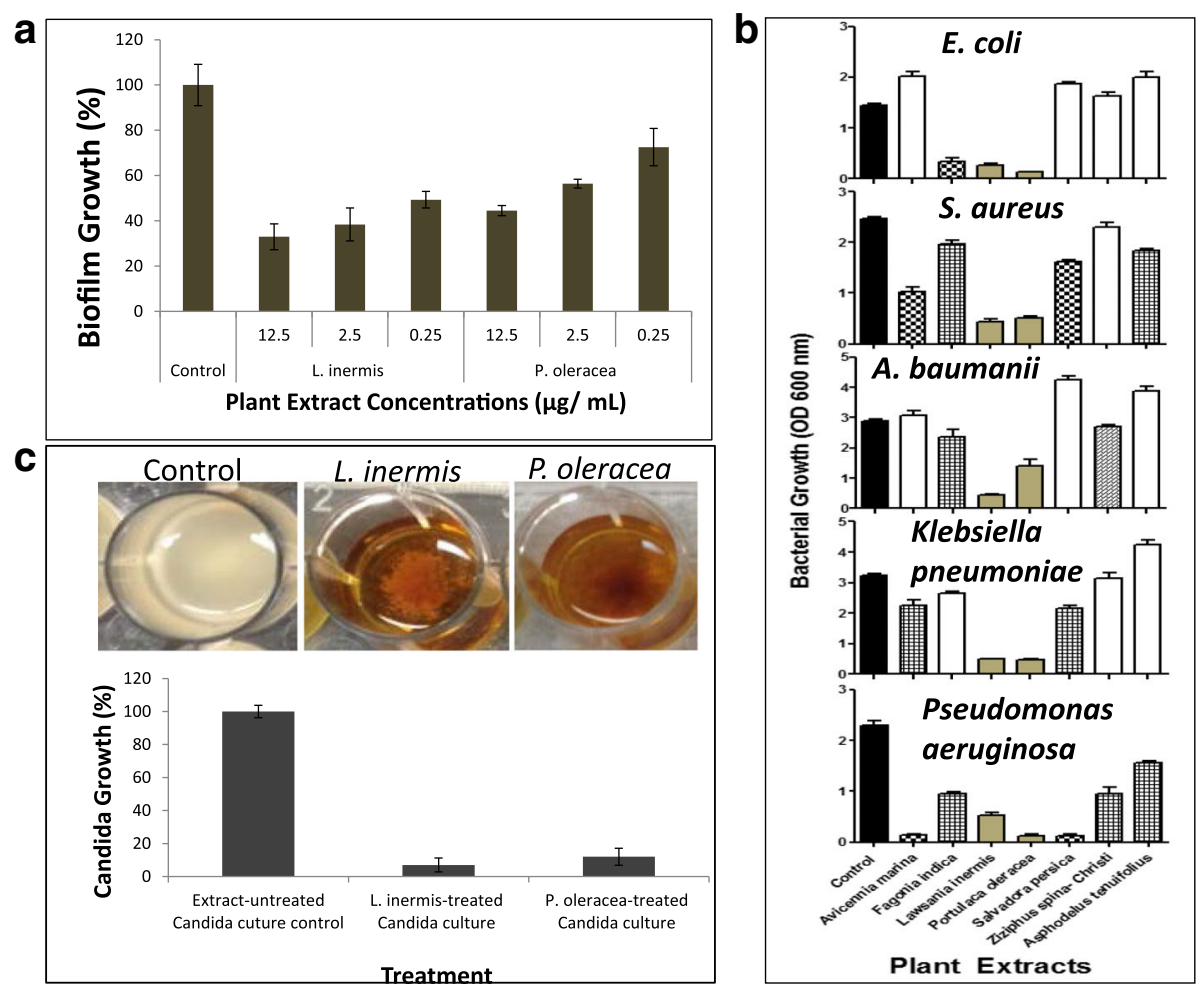

Fig. 1 Antimicrobial activities of alcoholic plant extracts. a Quantitative microtiter plate assay for biofilm formation using MTT method. The effect of both $L$. inermis and $P$. oleracea plants extracts were tested on C. albicans compared to no extract as negative control. $\mathbf{b}$ Bacterial growth inhibition by crude alcoholic plant extracts. The effect of alcoholic plant extracts on the growth of E. coli, S. aureus, Acinetobacter baumanii, Klebsiella pneumoniae, and Pseudomonas aeruginosa was tested in 24-well micro-plates. c Influence of L. inermis and P. oleracea alcoholic extracts on $24 \mathrm{~h}$-grwoing C. albicans in batch culture. The graph represents the re-inoculation of either alcoholic plant extracts-treated Candida or untreated cultures into fresh antibiotic-free media followed by incubation at $37^{\circ} \mathrm{C}$ for $24 \mathrm{~h}$. The data was analyzed using one-way analysis of variance (ANOVA) using Dunnett's Multiple Comparison Test. $P$ value $<0.05$ was considered as significant. The standard error represents the mean of three replicas

Table 4 Minimum inhibitory concentration (MIC) values in $\mu \mathrm{g} / \mathrm{mL}$ of alcoholic plant extracts against C. albicans in $24 \mathrm{~h}$ incubation period. MIC is the lowest concentration of plant extracts that inhibited microbial growth

\begin{tabular}{|c|c|c|c|c|c|c|}
\hline \multirow[b]{2}{*}{ Microbes } & \multicolumn{6}{|c|}{$\mathrm{MIC}(\mu \mathrm{g} / \mathrm{mL})$} \\
\hline & C. albicans & E. coli & S. aureus & P. aeruginosa & A. baumannii & K. pneumoniae \\
\hline A. marina & ND & ND & $10 \pm 0.8$ & $2.5 \pm 0.6$ & ND & $50 \pm 0.4$ \\
\hline F. indica & ND & $5 \pm 1.3$ & $50 \pm 1.6$ & $25 \pm 0.4$ & $25 \pm 0.9$ & $50 \pm 0.7$ \\
\hline L. inermis & $10 \pm 1.3$ & $5 \pm 0.4$ & $2.5 \pm 0.5$ & $5 \pm 1.2$ & $2.5 \pm 0.5$ & $2.5 \pm 0.6$ \\
\hline P. oleracea & $10 \pm 0.2$ & $2.5 \pm 0.3$ & $5 \pm 0.2$ & $2.5 \pm 0.4$ & $10 \pm 1.2$ & $2.5 \pm 0.1$ \\
\hline S. persica & $25 \pm 0.5$ & ND & $25 \pm 1.2$ & $2.5 \pm 0.6$ & ND & $50 \pm 1.4$ \\
\hline Z. spina-Christi & ND & ND & $50 \pm 0.4$ & $25 \pm 1.1$ & $25 \pm 0.4$ & $100 \pm 0.5$ \\
\hline A. tenuifolius & $50 \pm 0.4$ & ND & $25 \pm 0.7$ & $50 \pm 0.6$ & ND & ND \\
\hline Ketoconazole & $1 \pm 0.25$ & - & - & - & - & - \\
\hline Colistin & - & $2.5 \pm 0.5$ & - & $0.7 \pm 0.2$ & $1.25 \pm 0.25$ & $10 \pm 0.75$ \\
\hline Vancomycin & - & - & $10 \pm 0.5$ & - & - & - \\
\hline
\end{tabular}




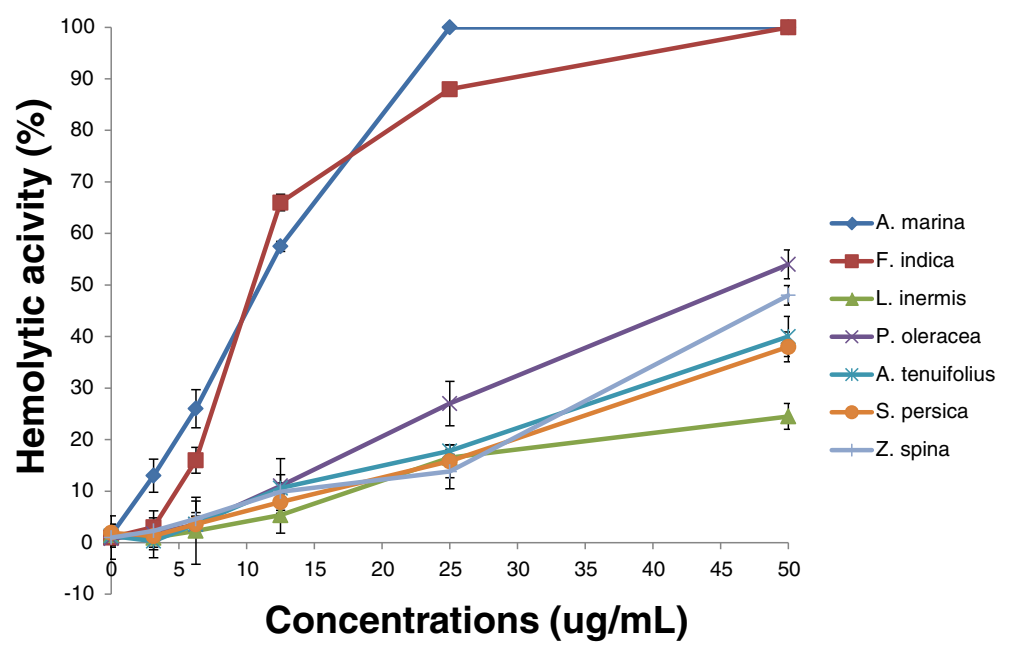

Fig. 2 Dose-dependent hemolytic activity of alcoholic plant extracts to human erythrocytes. DPBS-washed erythrocytes $\left(3 \times 10^{6}\right.$ cells per well) were incubated in 96-well plate with the total plant extracts at different concentrations (ranging from 3.6 to $100 \mu \mathrm{gg} / \mathrm{mL}$ ) at $37^{\circ} \mathrm{C}$ for $30 \mathrm{~min}$. The hemoglobin released from lysed erythrocytes was measured using micro-plate reader at $405 \mathrm{~nm}$. The absorbance values for each sample were subtracted from the absorbance value of cells treated only with washing buffer and the hemolytic activity (\%) was calculated. The experiment was conducted in triplicate

range of temperatures making them adequate for long storage, and different handling environment. These stability features make both extracts desirable for further development as potential antifungal agents [61].

\section{Selection based on extract safety}

The adverse drug effects associated with the use of antimicrobials can be of a major concern especially with antifungal agents due to the eukaryotic nature of the organism being targeted. Therefore, it is important to test the toxicity of plant extracts prior to application as antimicrobials. Among the cytotoxicity tests is hemolytic activity assay of human erythrocytes [62]. A cytotoxicity assay was conducted by testing different plant extracts at different concentrations and by using fresh human erythrocytes. The results showed that all plant extracts under study except $A$. marina and $F$. indica are safe and not toxic at a wide range of growth inhibitory concentrations (3-30 $\mu \mathrm{g} / \mathrm{mL}$ ) (Fig. 2). Both CC50 (cytotoxicity) and selective activity of the plant extracts were measured (Table 5). Our data show that both L. inermis and P. oleracea exhibit high selective antimicrobial activities. The relatively high selectivity indices of both $L$. inermis and $P$. oleracea indicate that both extracts are likely useful in managing infections due to $C$. albicans and other bacterial infections in humans [43]. The total activity of both $L$. inermis and $P$. oleracea plants were also calculated as 1.7 and $2.1 \mathrm{~mL} / \mathrm{g}$, respectively indicative of higher potency of both plants against $C$. albicans. And the results from this research indicate that both $L$. inermis and $P$. oleracea plants could be promising antimicrobials once they promoted for in vivo and clinical studies.

\section{Conclusion}

Several medicinal plants have been shown to have promising antimicrobial activities in vitro. However, to date there has been little interest in developing these medicinal plants as a source for producing novel drugs against infectious diseases. We show that $L$. inermis and

Table 5 Selective indices values of alcoholic plant extracts against C. albicans and bacterial pathogens

\begin{tabular}{|c|c|c|c|c|c|c|}
\hline \multirow[b]{2}{*}{ Microbes } & \multicolumn{6}{|l|}{$\mathrm{SI}$} \\
\hline & C. albicans & E. coli & S. aureus & P. aeruginosa & A. baumannii & K. pneumoniae \\
\hline A. marina & 0.2 & 0.13 & 1.3 & 5 & 0.13 & 0.3 \\
\hline F. indica & 0.12 & 2.5 & 0.25 & 0.4 & 0.6 & 0.21 \\
\hline L. inermis & 10 & 20 & 40 & 20 & 40 & 40 \\
\hline P. oleracea & 5 & 20 & 10 & 20 & 5 & 20 \\
\hline S. persica & 2.6 & 0.8 & 2.6 & 32 & 0.8 & 1.6 \\
\hline Z. spina-Christi & 0.6 & 0.6 & 1 & 2 & 3 & 0.9 \\
\hline A. tenuifolius & 1.8 & 0.7 & 2.3 & 1.4 & 0.7 & 0.7 \\
\hline
\end{tabular}


P. oleracea plants extracts have promising antimicrobial selectivity against $C$. albicans in its different dynamic forms of growth in vitro. Furthermore, both extracts showed significant antibacterial activity against multidrug resistant bacteria (MDR), that can complicate Candida infection through secondary mixed infections. Considering also the lower cytotoxicity and higher selectivity indices, both plant extracts represent promising area of future research that is likely to include in vivo testing, and determination of mechanism of action. Moreover, the active pure compounds from both plant extracts need to be determined which are likely to aid in determining the mechanism of action and the microbial target. Additionally, the ability of both plant extracts at sub-MIC concentrations to modulate the activity of available anti-Candida and Candida resistance can be addressed in future too. On the other hand, few other plant extracts from this research showed stimulatory effect on $C$. albicans and bacterial growth which can be used to stimulate the growth and detection of difficult-growing beneficial microflora including endophytes.

\section{Abbreviations}

ANOVA: One-way analysis of variance; BSA: Bovine serum albumin; C albicans: Candida albicans; CC50: Cytotoxic concentration of the extracts to cause death to $50 \%$ of viable cells; CFU: Colony-forming unit; CLSI: Clinical and Laboratory Standards Institute; DPBS: Dulbecco's phosphate-buffered saline; ICU: Intensive care units; IRB: Institutional review board; LA: Los Angeles; LB: Luria-Bertani; MDR: Multidrug resistant; MFC: Minimum fungicidal concentrations; MIC: Minimum inhibitory concentration; MTT: 3-(4,5-Dimethylthiazol-2-yl)-2,5-diphenyl tetrazolium bromide; $\mathrm{OD}_{600}$ : Optical density of a sample measured at a wavelength of $600 \mathrm{~nm}$; PBS: Phosphate-buffered saline; $P$-value: Probability value; RPMI: Roswell Park Memorial Institute medium; SI: Selectivity Index; U.A.E.: United Arab Emirates

\section{Acknowledgments}

We thank Mr. Amar (University Hospital Sharjah) for helping on the antiCandida activities of plant extracts. We also thank Abrar Alsaadi (California State University, Dominguez Hills) for helping on the cytotoxic activities of the plant extract.

\section{Funding}

This work was supported by grants from University of Sharjah, U.A.E. (1601110215-P) to S.S and by a Public Health Service grants R01 Al063503 to A.S.I.

The funding sources had no involvement in study design, analysis of data, writing the manuscript or the decision to submit the paper for publication.

\section{Availability of data and materials}

The data sets analyzed during the current study available from the corresponding author on reasonable request.

\section{Authors' contributions}

SS: Prepared the plants extracts, performed the antimicrobial, susceptibility and cytotoxicity assays, data analysis and drafted the manuscript MS: assisted with data analysis and design of manuscript AK: collected the plant material, taxonomic classification and writing revision AA: assisted with the anti-Candida assay PU: assisted with the anti-biofilm formation assay Al: coordinated the overall work, assisted the antimicrobial assay and toxicity study, interpreted the data and help in preparing the manuscript. Finally, all authors read and approved the final manuscript.

\section{Competing interests}

We wish to confirm that there are no known competing interests associated with this publication.
Consent for publication

Not applicable.

Ethics approval and consent to participate

Informed consent was obtained from donor for the use of his blood. All experimental procedures were approved by Institutional Review Board (IRB) of LA Biomed under protocol R01 Al063503.

\section{Publisher's Note}

Springer Nature remains neutral with regard to jurisdictional claims in published maps and institutional affiliations.

\section{Author details \\ 'Department of Medicinal Chemistry, College of Pharmacy, University of Sharjah, SharjahPO Box 27272 United Arab Emirates. ${ }^{2}$ Sharjah Institute for Medical Research, University of Sharjah, Sharjah, United Arab Emirates. ${ }^{3}$ Department of Applied Biology, University of Sharjah, Sharjah, United Arab Emirates. ${ }^{4}$ University Hospital Sharjah, Sharjah, United Arab Emirates. ${ }^{5}$ Division of Infectious Diseases, Los Angeles Biomedical Research Institute, Harbor-UCLA Medical Center, Torrance, CA, USA. ${ }^{6}$ David Geffen School of Medicine at UCLA, Los Angeles, CA, USA. ${ }^{7}$ Permanent address: Department of Pharmacognosy, Faculty of Pharmacy, University of Zagazig, Zagazig, Egypt.}

Received: 13 January 2017 Accepted: 28 April 2017

Published online: 08 May 2017

\section{References}

1. Inghammar M, Engström G, Ljungberg B, Löfdahl C-G, Roth A, Egesten A. Increased incidence of invasive bacterial disease in chronic obstructive pulmonary disease compared to the general population-a population based cohort study. BMC Infect Dis. 2014;14(1):163.

2. Spellberg B, Guidos R, Gilbert D, Bradley J, Boucher HW, Scheld WM, Bartlett $J G$, Edwards J. America tIDSo. The epidemic of antibiotic-resistant infections: A call to action for the medical community from the infectious diseases society of America. Clin Infect Dis. 2008;46(2):155-64.

3. Ventola CL. The antibiotic resistance crisis: Part 1: Causes and threats. Pharm Ther. 2015;40(4):277-83.

4. Poulin M-C, Villeneuve J. Drug Shortages: A public health issue that demands a coordinated response. Recommendations of the working committee on drug shortages. Québec: Ordre des pharmaciens du Québec; 2012

5. Dancer SJ. How antibiotics can make us sick: the less obvious adverse effects of antimicrobial chemotherapy. Lancet Infect Dis. 2004;4:611-9.

6. Stefano D, Paolo M, Marianna I, Sonia M, Margherita S. Discovering new bioactive molecules from microbial sources. Microb Biotechnol. 2014; 7(3):209-20

7. White TC, Marr KA, Bowden RA. Clinical, cellular, and molecular factors that contribute to antifungal drug resistance. Clin Microbiol Rev. 1998;11(2):382-402.

8. d'Enfert C. Hidden killers: Persistence of opportunistic fungal pathogens in the human host. Curr Opin Microbiol. 2009;12(4):358-64

9. Rees JR, Pinner RW, Hajjeh RA, Brandt ME, Reingold AL. The epidemiological features of invasive mycotic infections in the San Francisco bay area, 1992-1993: Results of population-based laboratory active surveillance. Clin Infect Dis. 1998:27(5):1138-47.

10. Vazquez JA, Sanchez V, Dmuchowski C, Dembry LM, Sobel JD, Zervos MJ. Nosocomial acquisition of Candida albicans: An epidemiologic study. J Infect Dis. 1993;168(1):195-201.

11. Wisplinghoff $H$, Bischoff $T$, Tallent SM, Seifert $H$, Wenzel RP, Edmond MB. Nosocomial bloodstream infections in US hospitals: Analysis of 24,179 cases from a prospective nationwide surveillance study. Clin Infect Dis. 2004;39(3):309-17.

12. Trick WE, Fridkin SK, Edwards JR, Hajjeh RA, Gaynes RP. Secular trend of hospital-acquired candidemia among intensive care unit patients in the united states during 1989-1999. Clin Infect Dis. 2002;35(5):627-30.

13. Mukherjee PK, Chandra J. Candida biofilm resistance. Drug Resist Updat. 2004; $7(4): 301-9$

14. Brand A. Hyphal growth in human fungal pathogens and its role in virulence. Int J Microbiol. 2012;2012:1-11.

15. Kojic EM, Darouiche RO. Candida infections of medical devices. Clin Microbiol Rev. 2004;17(2):255-67. 
16. Rodney MD. Biofilms and device-associated infections. Emerg Infect Dis J. 2001;7(2):277.

17. DiDone L, Oga D, Krysan DJ. A novel assay of biofilm antifungal activity reveals that amphotericin B and caspofungin lyse Candida albicans cells in biofilms. Yeast. 2011;28(8):561-8.

18. Humber JM. The role of complementary and alternative medicine: accommodating pluralism. JAMA. 2002;288(13):1655-6.

19. Bishop FL, Lewith G. Who uses CAM? A narrative review of demographic characteristics and health factors associated with CAM use. Evid Based Complement Alternat Med. 2010;7(1):11-28.

20. Ebrahimy F, Dolatian M, Moatar F, Majd HA. Comparison of the therapeutic effects of Garcin ${ }^{\oplus}$ and fluconazole on Candida vaginitis. Singap Med J. 2015; 56(10):567-72

21. Varadarajan S, Narasimhan M, Malaisamy M, Duraipandian C. Invitro anti-mycotic activity of hydro alcoholic extracts of some indian medicinal plants against fluconazole resistant Candida albicans. J Clin Diagn Res. 2015;9(8):ZC07-10.

22. Dhamgaye S, Devaux F, Vandeputte P, Khandelwal NK, Sanglard D, Mukhopadhyay G, Prasad R. Molecular mechanisms of action of herbal antifungal alkaloid berberine, in Candida albicans. PLoS One. 2014;9(8): e104554.

23. Liu X, Han Y, Peng K, Liu Y, Li J, Liu H. Effect of traditional chinese medicinal herbs on Candida spp. From patients withHIV/AIDS. Adv Dent Res. 2011; 23(1):56-60

24. Soares $I H$, Loreto ÉS, Rossato L, Mario DN, Venturini TP, Baldissera F, Santurio $\mathrm{JM}$, Alves SH. In vitro activity of essential oils extracted from condiments against fluconazole-resistant and -sensitive Candida glabrata. J Med Mycol. 2015;25(3):213-7.

25. Haba E, Bouhdid S, Torrego-Solana N, Marqués AM, Espuny MJ, GarcíaCelma MJ, Manresa A. Rhamnolipids as emulsifying agents for essential oil formulations: Antimicrobial effect against Candida albicans and methicillinresistant Staphylococcus aureus. Int J Pharm. 2014;476(1-2):134-41.

26. Vale-Silva L, Silva M-J, Oliveira D, Gonçalves M-J, Cavaleiro C, Salgueiro L, Pinto E. Correlation of the chemical composition of essential oils from Origanum vulgare subsp. virens with their in vitro activity against pathogenic yeasts and filamentous fungi. J Med Microbiol. 2012;61(2):252-60.

27. Authority H. Encyclopedia of Medicinal Plants of UAE, vol. 1. Abu Dhabi: Zayed Center for Herbal Research. Zayed Complex for Herbal Research and Traditional Medicine (ZCHRTM); 2005.

28. Mahasneh AM. Screening of some indigenous Qatari medicinal plants for antimicrobial activity. Phytother Res. 2002;16(8):751-3.

29. Singh VK, Pandey DK. Fungitoxic studies on bark extract of Lawsonia inermis against ringworm fungi. Hindustan Antibiot Bull. 1989;31(1-2):32-5.

30. Oh K-B, Chang I-M, Hwang K-J, Mar W. Detection of antifungal activity in Portulaca oleracea by a single-cell bioassay system. Phytother Res. 2000; 14(5):329-32.

31. Halawany HS. A review on miswak (Salvadora persica) and its effect on various aspects of oral health. Saudi Dent J. 2012;24(2):63-9.

32. Ezoddini-Ardakani F. Efficacy of miswak (Salvadora persica) in preventing dental caries. Health (N Y). 2010;2:499-503.

33. Naseem S, Hashmi K, Fasih F, Sharafat S, Khanani R. In vitro evaluation of antimicrobial effect of miswak against common oral pathogens. Pak J Med Sci. 2014;30(2):398-403.

34. Shahat AA, Pieters L, Apers S, Nazeif NM, Abdel-Azim NS, Berghe DV, Vlietinck AJ. Chemical and biological investigations on Zizyphus spina-christi L. Phytother Res. 2001;15(7):593-7.

35. Kirkpatrick WR, McAtee RK, Revankar SG, Fothergill AW, McCarthy DI, Rinaldi MG, Patterson TF. Comparative evaluation of national committee for clinical laboratory standards broth macrodilution and agar dilution screening methods for testing fluconazole susceptibility of Cryptococcus neoformans. J Clin Microbiol. 1998:36(5):1330-2.

36. European Committee for Antimicrobial Susceptibility Testing of the European Society of Clinical M, Infectious D. Determination of minimum inhibitory concentrations (MICS) of antibacterial agents by broth dilution. Clin Microbiol Infect. 2003;9(8):ix-xv

37. Eloff JN. Quantification the bioactivity of plant extracts during screening and bioassay guided fractionation. Phytomedicine. 2004;11(4):370-1.

38. Espinel-Ingroff A, Fothergill A, Peter J, Rinaldi MG, Walsh TJ. Testing conditions for determination of minimum fungicidal concentrations of new and established antifungal agents for Aspergillus spp.: NCCLS collaborative study. J Clin Microbiol. 2002;40(9):3204-8.
39. Pierce CG, Uppuluri P, Tristan AR, Wormley FL, Mowat E, Ramage G, LopezRibot JL. A simple and reproducible 96-well plate-based method for the formation of fungal biofilms and its application to antifungal susceptibility testing. Nat Protoc. 2008:3(9):1494-500.

40. Nuryastuti T, van der Mei HC, Busscher HJ, Iravati S, Aman AT, Krom BP. Effect of cinnamon oil on icaa expression and biofilm formation by Staphylococcus epidermidis. Appl Environ Microbiol. 2009;75(21):6850-5.

41. Bokori-Brown M, Martin TG, Naylor CE, Basak AK, Titball RW, Savva CG. CryoEM structure of lysenin pore elucidates membrane insertion by an aerolysin family protein. Nat Commun. 2016;7:11293.

42. Stark M, Liu L-P, Deber CM. Cationic hydrophobic peptides with antimicrobial activity. Antimicrob Agents Chemother. 2002;46(11):3585-90.

43. Bagla VP, McGaw LJ, Elgorashi EE, Eloff JN. Antimicrobial activity, toxicity and selectivity index of two biflavonoids and a flavone isolated from Podocarpus henkelii (Podocarpaceae) leaves. BMC Complement Altern Med. 2014;14:383.

44. Serrano-Fujarte I, Lopez-Romero E, Reyna-Lopez GE, Martinez-Gamez MA, Vega-Gonzalez A, Cuellar-Cruz M. Influence of culture media on biofilm formation by Candida species and response of sessile cells to antifungals and oxidative stress. Biomed Res Int. 2015;2015:15.

45. O'Connor L, Caplice N, Coleman DC, Sullivan DJ, Moran GP. Differential filamentation of Candida albicans and Candida dubliniensis is governed by nutrient regulation of UME6 expression. Eukaryot Cell. 2010;9(9):1383-97.

46. Loeb JDJ, Sepulveda-Becerra M, Hazan I, Liu H. A G(1) cyclin is necessary for maintenance of filamentous growth in Candida albicans. Mol Cell Biol. 1999; 19(6):4019-27.

47. Ahn Y-J, Sakanaka S, Kim M-J, Kawamura T, Fujisawa T, Mitsuoka T. Effect of green tea extract on growth of intestinal bacteria. Microb Ecol Health Dis. 1990;3(6):335-8

48. Muter O, Versilovskis A, Scherbaka R, Grube M, Zarina D. Effect of plant extract on the degradation of nitroaromatic compounds by soil microorganisms. J Ind Microbiol Biotechnol. 2008;35(11):1539-43.

49. Sudbery P, Gow N, Berman J. The distinct morphogenic states of Candida albicans. Trends Microbiol. 2004;12(7):317-24.

50. Sudbery PE. Growth of Candida albicans hyphae. Nat Rev Microbiol. 2011; 9(10):737-48.

51. Filler SG, Sheppard DC. Fungal invasion of normally non-phagocytic host cells. PLoS Pathog. 2006;2(12):e129.

52. Chen $\mathrm{H}$, Fujita $\mathrm{M}$, Feng $\mathrm{Q}$, Clardy J, Fink GR. Tyrosol is a quorum-sensing molecule in Candida albicans. Proc Natl Acad Sci U S A. 2004;101(14):5048-52.

53. De Sordi L, Mühlschlegel FA. Quorum sensing and fungal-bacterial interactions in Candida albicans: A communicative network regulating microbial coexistence and virulence. FEMS Yeast Res. 2009:9(7):990-9.

54. Jenkinson H, Douglas L. Interactions between Candida Species and bacteria in mixed infections. In: Brogden KA, Guthmiller JM, editors. Polymicrobial Diseases. edn. Washington (DC): ASM Press; 2002.

55. Johnson B, White RJ, Williamson GM. Factors influencing the susceptibility of Candida albicans to the polyenoic antibiotics nystatin and amphotericin B. J Gen Microbiol. 1987;104:325-33.

56. Hammond SM, Kliger BN. Mode of action of the polyene antibiotic candicidin: binding factors in the wall of Candida albicans. Antimicrob Agents Chemother. 1976;9(4):561-8.

57. Hammond SM, Kliger BN. Studies on the role of the cell wall of Candida albicans in the mode of action of polyene antibiotics. Proc Soc Gen Microbiol. 1974:1:45.

58. Gale EF. The release of potassium ions from Candida albicans in the presence of polyene antibiotics. J Gen Microbiol. 1974;80:451-65.

59. Westwater C, Balish E, Schofield DA. Candida albicans-conditioned medium protects yeast cells from oxidative stress: A possible link between quorum sensing and oxidative stress resistance. Eukaryot Cell. 2005;4(10):1654-61.

60. Bailie G, Kane M. Stability of drug additives to peritoneal dialysate. Perit Dial Int. 1995;15(8):328-35.

61. Arya SC, Agarwal N. Antimicrobial storage and antibiotic resistance. J Am Board Fam Med. 2008;21(2):168.

62. Juvvadi $P$, Vunnam $S$, Merrifield RB. Synthetic melittin, its enantio, retro, and retroenantio isomers, and selected chimeric analogs: their antibacterial, hemolytic, and lipid bilayer action. J Am Chem Soc. 1996;118(38):8989-97. 